\title{
QUESTÕES PRELIMINARES A CONSIDERAR PARA O ENSINO DO DIREITO AMBIENTAL NO ÂMBITO DA PÓS-GRADUAÇÃO STRICTO SENSU ${ }^{1}$
}

\section{PRELIMINARY ISSUES TO BE CONSIDERED FOR THE TEACHING OF ENVIRONMENTAL LAW IN THE FRAMEWORK OF POSTGRADUATION STRICTO SENSU}

\author{
Reginaldo Pereira ${ }^{2}$ \\ https://orcid.or/0000-0001-9943-9125
}

Submissão: 17/02/2021 / Aceito: 28/06/2021 / Publicado: 13/08/2021

\begin{abstract}
Resumo
O artigo tem como objetivo problematizar acerca de algumas questões que antecedem a preparação de disciplinas dedicadas ao estudo do direito ambiental em cursos de pós-graduação stricto sensu de direito, no Brasil. Apesar de estarem direcionadas a uma área específica, as questões nele ventiladas podem ser aproveitadas para componentes integrantes de matrizes curriculares de outros cursos correlatos. O texto, fruto de observações empíricas feitas durante anos de atuação como docente, inicialmente em cursos de graduação e, posteriormente, em cursos de especialização e mestrado em direito, reflete preocupações quanto à delimitação do papel e local do direito na proteção do meio ambiente; à natureza jurídica de seu objeto de tutela e à instrumentalidade de seus princípios e mecanismos. A pesquisa que originou o texto é analítica, de caráter teórico-qualitativo. O método adotado é o dedutivo. Conclui-se que o ensino do direito ambiental passa por uma contínua crítica que coloca em xeque suas bases estruturantes e epistemológicas.
\end{abstract}

Palavras-chave: Epistemologia jurídica. Direito ambiental. Principiologia ambiental.

\begin{abstract}
The article aims to problematize some issues that precedes the preparation of disciplines dedicated to the study of environmental law in stricto-sensu graduate law courses in Brazil. Despite being directed to a specific area, the questions raised here can be used for components that are part of the curricular matrices of other related courses. The text, result of empirical observations made during years of experience as a teacher, initially in undergraduate courses and, later, in specialization courses and master's degrees in law, reflects concerns about the delimitation of law's role and location in protecting the environment; the legal nature of the object of protection and the instrumentality of its principles and mechanisms. The research that originated this text is analytical, of theoretical and qualitative character. The method adopted is the deductive one. It is concluded that the teaching of environmental law goes through a continuous criticism that calls to question its structural and epistemological bases.
\end{abstract}

Keywords: Legal epistemology. Environmental law. Environmental principles.

\footnotetext{
${ }^{1}$ Texto preparatório para a disciplina Direito Ambiental, Cidadania e Sustentabilidade do PPGD da Unochapecó.

2 Doutor em Direito (UFSC). Professor do Programa de Pós-Graduação stricto sensu em Direito (Unochapecó). Líder do Grupo de Pesquisa Direito, Democracia e Participação Cidadã (Unochapecó). Membro da Rede de Pesquisa Nanotecnologia, Sociedade e Ambiente (RENANOSOMA).
} 


\section{INTRODUÇÃO}

As ementas dos planos de ensino dos componentes direito ambiental oferecidos nas graduações em direito das Instituições de Ensino Superior brasileiras, via de regra, podem ser divididas em três grandes grupos.

Em um primeiro se encontram aquelas que adotam estratégias de abordagem mais conceituais, a articular conteúdos provenientes de distintas áreas do conhecimento, notadamente da ecologia, ciências ambientais, economia, geografia, ecologia política, ética, entre outras, com uma base considerável de direito constitucional, administrativo, civil e penal, com o intuito de apresentar a estrutura das tutelas constitucional, administrativa, penal e civil ambientais brasileiras.

Estes modelos, com todas as variações, possibilitam ao estudante uma visão enciclopédica em relação a conceitos como ecossistema, geossistema, desenvolvimento sustentável, meio ambiente etc., ao passo que o instiga ao aprofundamento das principais questões de ordem jurídica sobre diversos institutos adaptados de outros ramos do direito ao ambiental.

Uma abordagem de cunho conceitual/estruturalista permite, ainda, questionamentos sobre a efetividade e eficácia das estruturas de proteção do meio ambiente, centradas, no caso do Brasil, em políticas e sistemas.

Outro grupo é composto por ementários departamentalizados, focados em análises sobre políticas e sistemas voltados a alguns — geralmente os de maior visibilidade — setores cobertos pelo vasto manto do direito ambiental. Processos ecológicos essenciais, espaços territoriais especialmente protegidos, governança de riscos de substâncias e produtos perigosos, atividades da mineração, energia nuclear, biodiversidade, biossegurança etc., são alguns exemplos.

Há ementários, a grande maioria — por sinal, que mesclam os dois primeiros grupos. Partem de uma parte introdutória, de caráter conceitual, trabalham com a estrutura das tutelas constitucional, administrativa, cível e penal do meio ambiente e preveem uma parte da carga horária para o trabalho de políticas ambientais setoriais.

O contínuo enxugamento dos cursos de graduação atrelado à super especialização que varre as matrizes curriculares, de um modo em geral, e à destinação de boa parte da carga horária para disciplinas clássicas como o direito civil, penal, processual civil e processual penal, impõem um ensino do direito ambiental de caráter eminentemente conteudista, no qual os professores se extenuam para apresentarem o máximo de conteúdo, no menor tempo possível. 
Se, na graduação, esta estratégia acaba afastando o interesse dos estudantes por temas ligados ao direito ambiental, em virtude do nível complexidade que a disciplina adquire, na pós-graduação stricto sensu, ela acaba formando profissionais com lacunas consideráveis.

O desafio que se coloca, então, é como pensar uma disciplina de direito ambiental que leve mestrandos e doutorandos a se aprofundarem em seus fundamentos.

A disciplina direito ambiental, cidadania e sustentabilidade do Programa de Pós-Graduação stricto sensu em Direito da Unochapecó foi pensada no Aplicativo de Proposta de Curso Novo como componente articulador entre três categorias centrais da área de concentração e da linha 1 (Direito, Cidadania e Socioambientalismo) do Curso de Mestrado: cidadania, sustentabilidade e direito.

Desde as primeiras pesquisas e dissertações, verificou-se a necessidade de aprofundar-se o campo teórico do direito ambiental, já que os conceitos operacionais cidadania e sustentabilidade eram e são suficientemente trabalhados em outros componentes da matriz curricular do curso.

Dessa forma, a partir da segunda ocasião em que foi oferecida, as discussões realizadas na disciplina privilegiaram os aspectos jurídicos das relações sociedade x natureza.

Não se trata de disciplina dogmática — até, porque, a dogmática encontra sérias limitações no campo da teoria do direito ambiental, - longe disso, é um componente que procura articular uma crítica - pretensiosamente coerente —, realizada a partir de elementos jurídicos endógenos, a um ramo novo do direito - por isso, suscetível a alterações de humores e incoerências que marcam tudo o que está na puberdade.

Por outro lado, abordagens de cunho intra-inter-multi-transdisciplinares são articuladas no sentido de privilegiarem o aspecto eminentemente jurídico do tema. Tal o é, pela necessidade de se delimitar o lugar do direito na proteção do meio ambiente; de se definir a natureza jurídica do objeto de tutela do direito ambiental e; de se contribuir para a construção de teorias que forneçam, nas palavras de Canotilho (2007, p. 164), “[...] categorias e conceitos de sistematização [...]” capazes de pôr em xeque o estado atual do direito ambiental.

Sem a mínima pretensão de esgotar o tema, o presente artigo sistematiza problematizações iniciais sobre estes três pontos.

\section{QUAL O LUGAR DO DIREITO NA PROTEÇÃO DO MEIO AMBIENTE?}

A resposta à questão, formulada a partir do livro de título praticamente homônimo, de autoria da jurista portuguesa Maria da Glória Garcia (2007), é obtida a partir de um exercício teórico de caráter residual/pluridimensional, que busca situar o direito como mais um entre outros campos do 
saber — ligados à ética, à ciência, à técnica, à ecologia, à economia e à política — que exercem papel relevante na proteção do meio ambiente.

Não se trata, no presente momento, de empreender um exercício sistêmico sobre as interpenetrações e os ruídos que cada um destes subsistemas exerce sobre os demais, o que demandaria um estudo aprofundado sobre a teoria dos sistemas sociais.

Trata-se, antes de tudo, de reconhecer que, se por um lado, o "[...] O direito isolado é um direito desarmado [...]" (CANOTILHO, 2007, p. 164), por outro, ao direito são reservadas funções específicas na tutela ambiental, decorrentes da própria natureza do direito.

Tal exercício objetiva não apenas situar o direito ante as demais áreas do conhecimento dotadas de legitimidade para falar e agir em defesa do equilíbrio ecológico, mas, principalmente, verificar como a relação entre tais campos não é, necessariamente, mutualista, pelo contrário.

No livro: Desconcerto do Leviatã, política e direito perante as incertezas da ciência, José Esteve Pardo (2015) retrata as dificuldades apresentadas pelo direito moderno para decidir a partir de pressupostos próprios, em virtude de ter sido construído sobre pressupostos das ciências modernas.

Garcia (2007, p. 11) também aborda o problema. Segundo a autora:

\begin{abstract}
Usando o poder de sugestão das metáforas, a regulamentação do ambiente assemelha-se a um cavalo de Tróia que entra para dentro das muralhas do direito, confiadamente, pelas mãos dos juristas, que lhe não reconhecem perigo. Uma vez aí, e sem que se sinta ou pressinta, por acção das forças expansivas que se escondem no interior dessa regulamentação, o direito tende a ser atingido no seu âmago, indiciando um processo de destruição idêntico ao que Tróia conheceu, em razão dos soldados inimigos acoitados no interior do cavalo de madeira, à espera da noite e do relaxamento das vulnerabilidades defensivas da cidade para saírem e a tomarem.
\end{abstract}

Canotilho (2007, p. 164), em recensão realizada ao livro de Maria da Glória Garcia, enfatiza que o perigo, ao qual se refere a autora, é o de "[...] um direito vergado ao discurso científico que, por sua vez, está vergado ao discurso do poder", o qual é exercido por um Estado que politicamente tem na técnica seu centro de poder, ou seja, de um Estado técnico, conforme definido por Helmut Schelsky (1965. p. 455), que se tornou “[...] um corpo técnico universal, e comprova sua eficiência estatal em grande parte pelo aperfeiçoamento das possibilidades técnicas da sociedade.”

Delimitar e problematizar acerca do lugar e do papel do direito na proteção do meio ambiente é medida proposta para, antes de qualquer finalidade, desanuviar os olhos dos estudantes sobre as possibilidades e limites do direito no atual emaranhado de questões ambientais.

Após a realização de tal exercício, é possível se tratar da natureza jurídica do objeto de tutela do direito ambiental. 


\section{QUAL A NATUREZA JURÍDICA DO OBJETO DE TUTELA DO DIREITO AMBIENTAL?}

Não obstante a legislação ambiental, em nível mundial, ter aumentado trinta e oito vezes, desde a Conferência de Estocolmo de 1972, dados da ONU (2019) indicam uma incapacidade generalizada dos países em fazer cumprir as novas leis ambientais, fato que, no plano internacional, representa um dos maiores desafios para a mitigação da mudança do clima, a redução da poluição e da extinção de espécies e habitats e, no âmbito interno, acaba ocasionando a baixa efetividade dos comandos constitucionais de proteção ao meio ambiente.

Tal paradoxo, delimitado ao contexto brasileiro, pode ser enfrentado a partir de análises relacionadas a três hipóteses não excludentes:

1) Há uma dificuldade exegética em relação ao caput do artigo 225 da Constituição Federal de 1988, em especial na delimitação do alcance do pronome "Todos" e das suas correlações com o “[...] direito ao meio ambiente ecologicamente equilibrado [...]" que subjaz à baixa concretude da garantia constitucional.

2) Há um esvaziamento incremental dos comandos constitucionais de tutela do meio ambiente, via legislação complementar ou ordinária regulamentadora dos dispositivos enumerados no parágrafo primeiro do artigo 225 e das disposições especiais constantes nos parágrafos segundo a sexto da Constituição Federal de 1988, que é operacionalizado mediante sucessivos retrocessos ecológicos e;

3) Há a incidência no ordenamento jurídico interno de fenômenos ligados à transnormatividade, decorrentes de interrelações e interpenetrações mantidas entre os direitos interno e internacional, e de normatividades — internas e externas —, muitas das quais de caráter infralegal, que acabam criando barreiras e subterfúgios para que o direito se concretize em benefício de interesses presentes e futuros ligados a determinados bens de uso comum do povo (como, por exemplo, o meio ambiente equilibrado e a vida saudável), e criando uma espécie de estrato ou estamento jurídico, no qual o direito cede sua centralidade para a tecnociência, pelo simples motivo de não deter legitimidade técnica para decidir, a partir de seus pressupostos, sobre questões de cunho tecnocientífico. A transnormatividade, além de ocasionar o enfraquecimento supra e sub legal da vontade do constituinte originário, importa na existência, em pleno Estado de Direito, de campos da ação econômica, cada vez mais centrais, nos quais o conhecimento tecnocientífico, e não o jurídico, determina as regras e limites da atuação do direito. 
Maior ênfase à dimensão interpretativa deste paradoxo revela que as relações entre a falta de clareza conceitual sobre os termos "todos" e "meio ambiente ecologicamente equilibrado", considerados elementos essenciais para a compreensão do alcance do artigo 225 da Constituição Federal de 1988, está intimamente ligada à baixa efetividade dos comandos e políticas constitucionais de proteção do meio ambiente, no Brasil.

A adequada definição da natureza jurídica do objeto do direito ambiental, passa por abordagens que privilegiem:

i) a integração e a interdependência entre os elementos de ordem física, química e biológica que compõem o meio ambiente;

ii) a forma aninhadora de organização dos sistemas ecológicos;

iii) a interação entre os ecossistemas e os geossistemas;

iv) a condição da qualidade ambiental como elemento fundante da ecologia política;

v) o resgate da sanidade ambiental como bem comum.

Além de definirem a natureza jurídica do objeto do direito ambiental, tais fatores condicionam as interpretações relativas aos direitos a ele correlatos.

O conteúdo do direito ao meio ambiente ecologicamente equilibrado se imbrica com o conceito jurídico do meio ambiente. No âmbito jurídico, é possível articular um conceito doutrinário, um conceito legal e um conceito constitucional do meio ambiente.

Para a doutrina, o meio ambiente é a soma do: i) meio ambiente natural: composto pelos elementos bióticos (fauna e flora) e abióticos (recursos naturais); ii) meio ambiente artificial: resultante da ação humana, subdivido em elementos fechados e abertos que propiciam uma sadia qualidade de vida nas cidades; iii) meio ambiente cultural: formado pelo patrimônio arqueológico, artístico, histórico, paisagístico e turístico.

O conceito legal de meio ambiente encontra-se elaborado no artigo $3^{\circ}$, I da Lei da Política Nacional do Meio Ambiente (L. 6938/81). Segundo tal dispositivo, o meio ambiente é o conjunto de condições, leis, influências e interações de ordem física, química e biológica, que permite, abriga e rege a vida em todas as suas formas.

Já o conceito constitucional de meio ambiente está inserido no artigo 225 da CF/88, segundo o qual: "Todos têm direito ao meio ambiente ecologicamente equilibrado, bem de uso comum do povo e essencial à sadia qualidade de vida, impondo-se ao poder público e à coletividade o dever de defendê-lo e preservá-lo para as presentes e futuras gerações." 
Da constitucionalização do direito ambiental decorre a necessária atualização do conceito de meio ambiente, o que impõe a conclusão que, na atualidade, o direito ambiental brasileiro compreende o meio ambiente como: i) um macrobem unitário e integrado, ii) um bem incorpóreo e imaterial; iii) um bem com configurações de microbem; iv) um bem de uso comum do povo, autônomo e de interesse público; v) um direito fundamental do homem, necessitando, para sua consecução, da participação e responsabilidade compartilhada do Estado e da Coletividade; e vi) um direito fundamental intergeracional, intercomunitário, pautado em uma política de Solidariedade. (LEITE, 2000).

Uma análise sistemática dos conceitos de meio ambiente permite concluir que: i) o meio ambiente ecologicamente equilibrado é um bem difuso - por ser de uso comum do povo e pertencer a todos - e intergeracional - das atuais e futuras gerações; ii) o meio ambiente ecologicamente equilibrado é condição para que todos possam usufruir de uma vida saudável, sendo portanto um direito fundamental; iii) o meio ambiente ecologicamente equilibrado comporta uma série de deveres de defesa e preservação para o Estado e a população.

Além disso, a configuração do meio ambiente como macrobem não afeta as características dos microbens que o integram. Tal noção importa em que se considere a qualidade ambiental em um duplo grau de aplicabilidade: i) a primeira relacionada às condições de sanidade ambiental que permite a vida no planeta (macrobem); e ii) a segunda relacionada à necessidade de serem mantidos os componentes desse bem maior ou seja, os microbens.

Uma das principais consequências da dupla definição do meio ambiente se reflete no campo dos direitos e deveres correlacionados.

A manutenção do equilíbrio ecológico constitui dever do Estado e de todos.

No campo dos direitos, tem-se que danos ao equilíbrio ecológico importam na violação autônoma de direitos de dimensões distintas: i) dimensão difusa, coletiva e individual homogênea (CDC, art. 81, parágrafo único, I, II e III).

A elevação do meio ambiente a status de direito fundamental reflete significativamente no campo da hermenêutica constitucional ambiental:

i) Por ser um direito fundamental (art. 225, Caput, c/c art. $5^{\circ}$ caput, c/c art. $5^{\circ}, \S 2^{\circ}$, todos da $\mathrm{CF} / 88$ ), a garantia de um meio ambiente saudável é de aplicabilidade imediata, ou seja, independe de qualquer regulamentação, vinculando o Estado à sua defesa e preservação - dever positivo, representado por verdadeiras obrigações de fazer - e impondo-lhe restrições à atuação como agente empreendedor — dever negativo, representado por obrigações de não fazer. 
ii) A equiparação aos direitos e garantias individuais constantes no artigo $5^{\circ}$, da $\mathrm{CF} / 88$, eleva o direito garantido no caput do artigo 225 da $\mathrm{CF} / 88$ à cláusula pétrea, ou seja, que não pode ser objeto de deliberação e Emenda Constitucional.

A natureza jurídica do meio ambiente reverbera, ainda, no campo da principiologia ambiental e na instrumentalidade dos dispositivos constitucionais aplicáveis.

A não consideração de todos e a equivocada visão antropocêntrica do artigo 225 da CF/88 impõe restrições à interpretação dos princípios do direito ambiental e à aplicação dos instrumentos inseridos no parágrafo único e nas disposições especiais do artigo, importando o tratamento das partes pelas partes e não pela totalidade.

Além do que, opera-se, na maioria das vezes de forma não intencional, uma cisão entre princípios e os instrumentos e mecanismos inseridos nos incisos do parágrafo primeiro, do artigo 225, da Constituição Federal com o objetivo de concretizar o comando insculpido no caput do artigo o qual, em última análise, procura amalgamar toda a principiologia ambiental.

Propõe-se, então, uma abordagem que privilegie a análise dos princípios e de seus instrumentos materializadores a partir da totalidade.

Com a finalidade de facilitar o desafio, indicam-se alguns elementos orientadores, que serão abordados a partir dos princípios do direito ambiental brasileiro.

\section{CONTRIBUIÇÕES PARA UMA LEITURA ATUALIZADA DOS PRINCÍPIOS DO DIREITO AMBIENTAL}

Realizou-se, em outra oportunidade, um exercício interpretativo com o objetivo de ressignificar os principais princípios do direito ambiental, a partir da ecologia natural ou científica ${ }^{3}$.

$\mathrm{Na}$ ocasião, procurou-se demonstrar como as principais vertentes exegéticas do direito ambiental brasileiro não consideravam elementos da ecologia científica no momento de preencher o conteúdo e determinar o alcance de princípios do direito ambiental.

Neste momento, busca-se indicar elementos a serem considerados na interpretação e concretização dos princípios do direito ambiental. Por falta de espaço, o exercício se centrará sobre os princípios mais significativos.

\section{Princípio do meio ambiente como direito fundamental}

\footnotetext{
${ }^{3}$ Ver: Reginaldo Pereira; Silvana Winckler; Gilza Maria de Souza Franco. Re-significação dos princípios do direito ambiental a partir da ecologia (2008).

DOI: https://doi.org/10.46699/rduno.v4i5.6096 | Edição Vol. 4, Núm. 5, 2021. 
Segundo este princípio, há um direito fundamental ao meio ambiente ecologicamente equilibrado que se encontra em pé de igualdade com outros direitos fundamentais previstos na Constituição Federal de 1988.

A interpretação corrente confere ao meio ambiente o status de direito fundamental, essencial para uma vida saudável, a ser desfrutado por todos os brasileiros e qualquer pessoa que se encontrar em território brasileiro.

Entende-se que a interpretação majoritária é adequada, todavia, para a devida interpretação do princípio, é necessário considerar inicialmente o contexto socioeconômico em que os direitos de terceira geração/dimensão emergiram, conforme a figura 1.

Figura 1. Contextos socioeconômicos no qual surgiram os direitos humanos/fundamentais

\begin{tabular}{|c|c|c|c|}
\hline & $\begin{array}{c}1^{\mathrm{a}} \\
\text { Geração/Dimensão }\end{array}$ & $\begin{array}{c}2^{\mathrm{a}} \\
\text { Geração/Dimensão }\end{array}$ & $\begin{array}{c}3^{\mathrm{a}} \\
\text { Geração/Dimensão }\end{array}$ \\
\hline Ano & 1789 & 1919 & 1968 \\
\hline Marco Histórico & $\begin{array}{c}\text { Revolução Francesa } \\
\text { França }\end{array}$ & Revolução Russa & $\begin{array}{l}\text { Maio de } 1968 \text { e } \\
\text { Primavera de Praga }\end{array}$ \\
\hline Local & & Rússia & $\begin{array}{c}\text { França e } \\
\text { Tchecoslováquia }\end{array}$ \\
\hline \multirow[t]{2}{*}{ Direitos } & $\begin{array}{c}\text { Público } \\
\text { (Constitucional) } \\
\text { e }\end{array}$ & $\begin{array}{c}\text { Sociais } \\
\text { (Tutela dos } \\
\text { hipossuficientes) }\end{array}$ & Metaindividuais \\
\hline & $\begin{array}{c}\text { Privado } \\
\text { (Civil e Comercial) }\end{array}$ & $\begin{array}{c}\text { Direito do } \\
\text { Trabalho, } \\
\text { Previdenciário, } \\
\text { Saúde, Educação, } \\
\text { etc. }\end{array}$ & $\begin{array}{c}\text { Direitos Difusos, } \\
\text { Coletivos e } \\
\text { Individuais } \\
\text { Homogêneos (art. } 81, \\
\text { § único, I-III do CDC } \\
\text { lei } 8.078 / 90\end{array}$ \\
\hline $\begin{array}{c}\text { Modelo de } \\
\text { Desenvolvimento }\end{array}$ & $\begin{array}{l}\text { Acumulação e } \\
\text { crescimento } \\
\text { econômico }\end{array}$ & $\begin{array}{c}\text { Crescimento } \\
\text { econômico e } \\
\text { distribuição de } \\
\text { riqueza } \square \text { Justiça } \\
\text { Social } \\
\end{array}$ & $\begin{array}{c}\text { Desenvolvimento } \\
\text { sustentável } \square \\
\text { Sustentabilidade }\end{array}$ \\
\hline $\begin{array}{c}\text { Verdade } \\
\text { (Campo Científico) }\end{array}$ & $\begin{array}{l}\text { Ciência positiva: } \\
\text { Enunciado não } \\
\text { contraditório e } \\
\text { comprovado } \\
\text { cientificamente }\end{array}$ & $\begin{array}{c}\text { Dialética: } \\
\text { Tese } \square \square \text { antítese: } \\
\text { Síntese }\end{array}$ & Sistêmica e holística \\
\hline
\end{tabular}




\begin{tabular}{|c|c|c|c|}
\hline Economia & $\begin{array}{c}\text { Mercado } \\
\text { (liberalismo } \\
\text { econômico) }\end{array}$ & $\begin{array}{c}\text { Industrial de Escala } \\
\text { (Capitalismo } \\
\text { dirigido) } \\
\text { Planificada } \\
\text { (Socialismo) }\end{array}$ & $\begin{array}{c}\text { Simbólica ou virtual } \\
\text { (Capitalismo } \\
\text { financeiro/ } \\
\text { globalização } \\
\text { econômica) }\end{array}$ \\
\hline $\begin{array}{l}\text { Movimento que } \\
\text { move a sociedade }\end{array}$ & Burguesia & Proletariado & $\begin{array}{c}\text { Novos movimentos: } \\
\text { ecologistas, pacifistas, } \\
\text { feministas, estudantis, } \\
\text { minorias, etc }\end{array}$ \\
\hline Valor & $\begin{array}{c}\text { Liberdade/ } \\
\text { igualdade formal }\end{array}$ & $\begin{array}{c}\text { Liberdade/ } \\
\text { igualdade material }\end{array}$ & Solidariedade \\
\hline Estado & Liberal & $\begin{array}{l}\text { Estado de bem- } \\
\text { estar social: } \\
\text { Social democracia; } \\
\text { liberalismo social }\end{array}$ & $\begin{array}{c}\text { Estado neoliberal } \\
\text { (estado de mal-estar } \\
\text { social) } \\
\text { Estado ambiental } \\
\text { (Estado de bem-estar } \\
\text { ambiental) }\end{array}$ \\
\hline
\end{tabular}

Fonte: Aula Professor Rogério Portanova (2012)

Os fundamentos constitucionais ligados ao direito à vida e à sadia qualidade de vida (artigo $5^{\circ}$, caput e $\S 2^{\circ}$ e art. 225, caput da Constituição Federal de 1988) e a natureza jurídica do direito são elementos a serem sopesados, pois, como já determinou o Supremo Tribunal Federal:

O direito à integridade do meio ambiente - típico direito de terceira geração — constitui prerrogativa jurídica de titularidade coletiva, refletindo, dentro do processo de afirmação dos direitos humanos, a expressão significativa de um poder atribuído, não ao indivíduo identificado em sua singularidade, mas, num sentido verdadeiramente mais abrangente, à própria coletividade social. Enquanto os direitos de primeira geração (direitos civis e políticos) - que compreendem as liberdades clássicas, negativas ou formais — realçam o princípio da liberdade e os direitos de segunda geração (direitos econômicos, sociais e culturais) - que se identificam com as liberdades positivas, reais ou concretas - acentuam o princípio da igualdade, os direitos de terceira geração, que materializam poderes de titularidade coletiva atribuídos genericamente a todas as formações sociais, consagram o princípio da solidariedade e constituem um momento importante no processo de desenvolvimento, expansão e reconhecimento dos direitos humanos, caracterizados, enquanto valores fundamentais indisponíveis, pela nota de uma essencial inexauribilidade. (STF, MS 22.164, rel. min. Celso de Mello, julgamento em 30-10-1995, Plenário, DJ de1711-1995.)

É preciso considerar ainda as relações entre os direitos à vida, à vida saudável e ao ambiente equilibrado e identificar as decorrências (cláusula pétrea e (im)possibilidade de retrocesso ambiental). 
Problematizações acerca da aceitação de tal direito no âmbito internacional, por meio do estudo do greening das Cortes e Tribunais Internacionais são muito bem vindas. ${ }^{4}$

Por fim, deve-se atentar para o que não é objeto, mas precisa ser posto em discussão: o conteúdo jurídico do pronome indefinido que abre o caput do artigo 225: "Todos".

\section{Princípios da precaução e da prevenção}

Conforme a sociedade de risco avança, medidas antecipatórias se fazem mais urgentes, dado a necessidade de serem evitadas catástrofes ambientais de grande potencial lesivo, dificuldades técnicas e altíssimos custos a serem despendidos com a recuperação ou indenização de agressões ao meio ambiente. Dessa forma, os dias atuais pedem, como regra, atitudes prevencionistas e precaucionistas.

O princípio da prevenção assegura o direito à tutela antecipada do meio ambiente ou do homem diante da iminência de um dano ambiental notório. Ele procura assegurar a tomada de medidas antecipadas, uma vez conhecido o perigo ou risco que se manifestará diante da inércia do agente público ou do cidadão, sendo, tal resultado, conhecido, até mesmo, pelo costume ou por experiências cotidianas ou científicas, já comprovadas.

O escopo do princípio da precaução é assegurar dos efeitos de uma ação imprudente cujo resultado seja incerto, mas tenha a probabilidade, estimativa de ocorrer.

O princípio de prevenção se aplica a situações nas quais respostas claras no plano científico existem, demonstrando que uma atividade ocasiona ou é potencialmente causadora de efeitos prejudiciais sobre o meio ambiente. Graças a esta certeza, a degradação ambiental pode ser impedida ou mitigada por uma intervenção na fonte dos danos. Na ausência de tal certeza científica deve ser aplicado o princípio de precaução.

Para uma adequada interpretação dos princípios, a primeira questão que se impõe é verificar se são princípios de governança de riscos e se prestam ao controle da produção, da comercialização e do emprego de técnicas, métodos e substâncias que comportem risco para a vida, a qualidade de

\footnotetext{
${ }^{4}$ Ver: José A. Sampaio. O esverdeamento da Convenção Europeia de Direitos Humanos: vícios e virtudes (2017); Valério de Oliveira Mazzuoli. O direito internacional do meio ambiente e o greening da Convenção Americana sobre Direitos Humanos (2013).
} 
vida e o meio ambiente, conforme determina o inciso $\mathrm{V}$, do parágrafo primeiro, do artigo 225 , da Constituição Federal de $1988 .^{5}$

Identificar as relações entre risco concreto e risco abstrato - e suas construções sociais (GARCÍA ACOSTA, 2005; SILVEIRA, 2015) - com os princípios é essencial para se determinar o alcance de cada um, na medida em que o princípio da precaução está ligado ao risco abstrato e o da prevenção, ao concreto. Situação de risco abstrato são diferentes das de risco concreto e requerem medidas antecipatórias adequadas. Além disso, o princípio da prevenção se aplica de forma mais corrente e fácil, quando comparado com o da precaução.

A precaução vem recebendo maior aprofundamento teórico do que a prevenção, devido ao caráter abstrato e o potencial paralisante do princípio. Por esse motivo, alguns dissensos sobre o princípio precisam ser explorados. O mais significativo é o que separa o princípio em forte e fraco. ${ }^{6}$

A precaução forte é aquela que preconiza tomadas de decisão com elementos menos concretos de riscos. Já a precaução fraca se aplica no caso de haver indicativos significativos de sua incidência, se aproximando da prevenção.

Ainda no campo da precaução, a identificação de modelos de aplicação, por meio de mapas e matrizes de gestão ou governança de risco é medida adequada, ainda que distancie o estudioso do campo do direito. ${ }^{7}$

Por fim, a problematização acerca do reforço da incidência da técnica sobre o direito pelos princípios, é medida que se impõe.

\section{Princípio do poluidor-pagador}

O princípio 16 da Declaração do Rio de Janeiro de 1992 fornece as bases conceituais do princípio do poluidor-pagador: “As autoridades nacionais deverão esforçar-se por promover a internalização dos custos ambientais e a utilização de instrumentos econômicos, tendo em conta o princípio de que o poluidor deverá, em princípio, suportar o custo da poluição, com o devido respeito pelo interesse público e sem distorcer o comércio e investimento".

\footnotetext{
${ }^{5}$ Ver: Poul F. Kjaer. La metamorfosis de la síntesis funcional. Una perspectiva europeo-continental sobre governance, derecho y lo político en el espacio transnacional (2010); Poul F. Kjaer. A função da legitimação na governança transnacional (2017). DI GIULIO, Gabriela Marques; FERREIRA, Lúcia da Costa. Governança do risco: uma proposta para lidar com riscos ambientais no nível local.

${ }^{6}$ Ver SUSTEIN, Cass R. Laws of fear: beyond the precautionary principle (2005).

${ }^{7}$ Ver: ARAGÃO, Alexandra. Princípio da precaução: manual de instruções (2008).
}

DOI: https://doi.org/10.46699/rduno.v4i5.6096 | Edição Vol. 4, Núm. 5, 2021. 
O princípio é inspirado pela teoria econômica de acordo com a qual os custos sociais externos que acompanham a produção industrial devem ser internalizados, ou seja, tidos em conta pelos agentes econômicos nos seus custos de produção.

O princípio do poluidor-pagador cumpre, na lição de Derani (1997, p. 158-159), uma dupla função: i) visa à internalização dos custos relativos externos de deterioração do meio ambiente, impondo ao utilizador de recursos naturais que possa causar um dano ambiental, arcar com os custos relativos à sua diminuição ou afastamento — neste sentido o princípio adquire um caráter preventivo (verursacherprinzip); ii) visa, também, à internalização das externalidades negativas decorrentes de processos produtivos que acabam sendo suportadas por toda a população, fazendo com que o utilizador de recursos naturais seja responsabilizado por elas - caráter reparatório (verantwortungsprinzip).

A constatação de que os recursos naturais são apropriados de forma gratuita passando a integrar o patrimônio de determinada pessoa em detrimento dos demais membros de uma comunidade localiza-se na base do princípio.

A questão que se impõe em relação à interpretação do princípio está relacionada à identificação das bases jurídicas e a dupla finalidade do princípio. ${ }^{8}$

Além disso, é preciso problematizar acerca das implicações que a adoção dos pressupostos da economia ecológica importaria para a sua interpretação ${ }^{9}$ e identificar os impactos da adoção de propostas antidesenvolvimentistas e decoloniais sobre sua aplicação.

\section{Princípio da participação}

A Constituição da República Federativa do Brasil de 1988 consagrou a atuação presente do Estado e da sociedade civil na proteção e preservação do meio ambiente.

São elementos fundamentais para a efetivação do princípio da participação: a informação ambiental, a existência de espaços de participação e a educação ambiental.

A informação ambiental encontra respaldo legal nos artigos $6^{\circ}, \S 3^{\circ}$ e 10 da Lei da Política Nacional do Meio Ambiente (Lei n. 6938/81). Por outro lado, a CF/88 assegura a todos, o direito à informação, sem restrição de qualquer natureza.

\footnotetext{
${ }^{8}$ Ver ARAGÃO, Alexandra. O princípio do poluidor pagador: pedra angular da política comunitária do ambiente (2014).

${ }^{9}$ Ver: CECHIN, Andrei Domingues; VEIGA, José Eli da. A economia ecológica e evolucionária de Georgescu-Roegen (2010). Ver: ROCHA, Jefferson Marçal da; AREND, Silvio Cezar. O erro histórico da ciência econômica: um resgate da obra de Georgescu-Roegen (2019).
}

DOI: https://doi.org/10.46699/rduno.v4i5.6096 | Edição Vol. 4, Núm. 5, 2021. 
A previsão de audiência pública em licenciamentos ambientais de empreendimentos potencialmente causadores de significativo impacto ambiental é exemplo de espaço de participação.

A educação ambiental decorre do princípio da participação na tutela do meio ambiente e está prevista na Constituição Federal, no art. $225, \S 1^{\circ}$, VI e deve ser promovida em todos os níveis de ensino.

Há um elemento a ser explorado com maior propriedade na interpretação do princípio e está ligado à capacidade do meio ambiente ser considerado nos processos decisórios. O estudioso deverá levar em consideração problematizações sobre a isegoria e a isonomia ambientais, intergeracionalidade do direito ao meio ambiente e sincronia e diacronia do direito ao meio ambiente.

\section{Princípio da natureza pública da proteção ambiental}

O meio ambiente deve ser assegurado e protegido para uso de todos e o artigo 225 da $\mathrm{CF} / 88$ elenca uma série de deveres a serem cumpridos pelo Estado para tal desiderato.

Assim, apesar de ser dotada de natureza, a proteção do equilíbrio ecológico é dotada de natureza pública.

Por força de tal princípio existiria uma ordem pública ambiental, segundo a qual o Estado asseguraria o equilíbrio entre o homem e seu ambiente.

O princípio impõe a atuação do Estado na defesa do meio ambiente e dá fulcro, inclusive, ao surgimento do que se vem denominando de Estado de Direito Ambiental.

A defesa do meio ambiente por um Estado ecologicamente orientado requer a adoção de medidas coercitivas, baseadas em instrumentos de comando e controle e medidas proativas em conjunto com a sociedade. Apesar de dar base à não indenização aos proprietários e agentes econômicos, por parte do Estado, em virtude de limites impostos na exploração da propriedade privada, é certo que a atuação baseada na indução, inclusive por meio de mecanismos econômicos, a práticas amigas do meio ambiente acaba sendo extremamente valiosa em um Estado que assume a proteção ambiental. ${ }^{10}$

10 Ver: KLOEPFER, Michael. A caminho do Estado Ambiental? (2016). Ver: IUCN. World Declaration on the Environmental Rule of Law (2016); UN ENVIRONMENT. Environmental Rule of Law: first global report; Ecological approaches to Environmental Law (2019); VOIGT, Christina. Rule of law for nature: new dimensions and ideas in Environmental Law (2013). 


\section{CONSIDERAÇÕES FINAIS}

A produção bibliográfica, em regra, visa contribuir para o avanço da comunidade científica, por meio da publicização dos resultados de pesquisas. Grande parte do que é produzido e divulgado possui caráter pontual, determinado pelos objetivos a serem atingidos em projetos com prazos prédefinidos nos projetos indicam os caminhos da investigação.

Há produtos, no entanto, resultantes de projetos de vida, construídos e sedimentados por anos de dedicação a determinadas atividades.

O presente artigo pertence ao segundo grupo. Ele é fruto de construções e desconstruções experimentadas em quase duas décadas de atividades de pesquisa, especialização e docência experimentadas em Cursos de Graduação e ao Programa de Pós-Graduação stricto sensu em Direito da Universidade Comunitária da Região de Chapecó - Unochapecó.

Sob o ponto de vista metodológico, o texto é despretensioso. Ele não apresenta resultados sistematizados de pesquisas do autor. O seu objetivo é causar incômodo aos estudantes que estão iniciando sua trajetória na pós-graduação em direito ambiental, daí seu caráter panorâmico.

A dedicação de boa parte do artigo aos principais princípios do direito ambiental resulta da constatação de quão mal compreendidos e abordados costumam ser e da convicção de que o ensino do direito ambiental passa por constantes críticas que coloquem em xeque suas bases estruturantes e epistemológicas.

\section{REFERÊNCIAS}

ARAGÃO, Alexandra. Princípio da Precaução: manual de instruções. Revista do CEDOUA, n. 22, p. 9-57, 2008.

ARAGÃO, Alexandra. O princípio do poluidor pagador: pedra angular da política comunitária do ambiente. São Paulo: Instituto o Direito por um Planeta Verde, 2014.

BOURDIEU, Pierre. Sociologia. Trad.: Paula Montero e Alicia Auzmendi. São Paulo: Ática, 1983.

CANOTILHO, José Joaquim Gomes. O lugar do Direito na protecção do ambiente. CEDOUA, n. 2, 2007, p. 163-164.

CECHIN, Andrei Domingues; VEIGA, José Eli da. A economia ecológica e evolucionária de Georgescu-Roegen. Economia Política, São Paulo, v. 30, n. 3, pág. 438-454, 2010.

DERANI, Cristiane. Direito ambiental econômico. São Paulo: Max Limonad, 1997. 
DI GIULIO, Gabriela Marques; FERREIRA, Lúcia da Costa. Governança do risco: uma proposta para lidar com riscos ambientais no nível local. Desenvolvimento e Meio Ambiente, Curitiba, v. 28, p. 29-39, 2013.

DREITZEL, Hans-Peter et all. Tecnocracia e ideologia. Trad.: Gustavo F. Bayer. Rio de Janeiro: Tempo Brasileiro, 1975.

GARCÍA ACOSTA, Virginia. El riesgo como construcción social y la construcción social de riesgos. Desacatos, n. 19, p. 11-24, 2005.

GARCIA, Maria da Glória F. P. D. O lugar do Direito na protecção do ambiente. Coimbra: Almedina, 2007.

IUCN. World Declaration on the Environmental Rule of Law. Disponível em: <http://iucnael2016.no/wp-content/uploads/2016/06/WORLD-DECLARATION-ON-THEENVIRONMENTAL-RULE-OF-LAW-Near-Final-Draft-.pdf>. Acesso: dez. 2016.

KJAER, Poul F. La metamorfosis de la síntesis funcional. Una perspectiva europeo-continental sobre governance, derecho y lo político en el espacio transnacional. Tradução Francisco Mujica. Wisconsin Law Review, p. 153-204, 2010.

KJAER, Poul F. A função da legitimação na governança transnacional. RDU, Porto Alegre, v. 14, n. 78, 2017, 177-196, 2017.

KLOEPFER, Michael. A caminho do Estado Ambiental? Tradução: Carlos Alberto Molinaro. Disponível em: https://www.google.com.br/webhp?sourceid=chrome-instant\&rlz=1C1CHZL_ptBRBR709BR709\&ion=1\&espv=2\&ie $=U T F-8 \# q=e s t a d o+d e+d i r e i t o+a m b i e n t a l+k l o e p f e r \& *$.

Acesso: dez. 2016.

LEITE, José Rubens Morato. Dano Ambiental: do individual ao coletivo extrapatrimonial. São Paulo: Editora Revista dos Tribunais, 2000.

LUHMANN, Niklas. Legitimação pelo procedimento. Brasília: UnB, 1980.

LUHMANN, Niklas. Sociologia do direito I. Trad.: Gustavo Bayer. Rio de Janeiro: Tempo Brasileiro, 1983.

LUHMANN, Niklas. Sociologia do Direito II. Trad.: Gustavo Bayer. Rio de Janeiro: Tempo Brasileiro, 1985.

MAZZUOLI, Valerio de Oliveira; TEIXEIRA, Gustavo de Faria Moreira. O direito internacional do meio ambiente e o greening da Convenção Americana sobre Direitos Humanos. Revista de Direito GV, São Paulo, v. 9, n. 1, p. 199-241, jun. 2013.

PARDO, José Esteve. O desconcerto do Leviatã: política e direito perante as incertezas da ciência. Tradução: Flávia França Dinnebier; Giorgia Sena Martins. São Paulo: Instituto o Direito por um Planeta Verde, 2015. 
PEREIRA, Reginaldo. WINCKLER, Silvana: O estado tecnocrático como obstáculo à realização da democracia. In: BEDIN, Gilmar (org.). Cidadania, justiça e controle social. Santa Cruz do Sul: Essere nel Mondo, 2016, p. 120-131.

PEREIRA, Reginaldo; WINCKLER, Silvana; FRANCO, Gilza Maria de S. Re-significação dos princípios do direito ambiental a partir da ecologia. Sequência, Florianópolis, v. 29, n. 56, p. 123150, set, 2008.

SAMPAIO, José A. O esverdeamento da Convenção Europeia de Direitos Humanos: vícios e virtudes. Questio Juris, v. 10, n. 2, p. 779-800, RJ, 2017.

ROCHA, Jefferson Marçal da; AREND, Silvio Cezar. O erro histórico da ciência econômica: um resgate da obra de Georgescu-Roegen. Desenvolvimento e Meio Ambiente, Curitiba, v. 52, p. 412424, 2019.

SILVEIRA, Clóvis Eduardo Malinverni da. A teoria da sociedade de risco como instrumento para a compreensão da emergência dos movimentos sociais urbanos no brasil: um contraponto crítico. Questio Juris, v. 8, n. 3, p. 1913-1948, RJ, 2015.

SUNSTEIN, Cass R. Laws of fear: beyond the precautionary principle. New York: Cambridge University Press, 2005.

UN ENVIRONMENT. Environmental Rule of Law: first global report; Ecological approaches to Environmental Law. Disponível em: https://www.unep.org/resources/assessment/environmentalrule-law-first-global-report. Acesso: jun. 2019.

VOIGT, Christina. Rule of law for nature: new dimensions and ideas in environmental law. Cambridge: Cambridge University Press, 2013. 